\title{
As plosivas nas séries iniciais: o papel do contexto na ocorrência de trocas ortográficas
}

\author{
The stops in the primary school: the role of the context in the occurrence \\ of orthographic changes
}

\author{
Vergília Spiering Damé \\ Pontifícia Universidade Católica do Rio Grande do Sul - PUCRS - Porto Alegre - Rio Grande do Sul - Brasil
}

\section{Giovana Ferreira-Gonçalves}

Universidade Federal de Pelotas - UFPEL - Pelotas - Rio Grande do Sul - Brasil

\begin{abstract}
Resumo: A presença de trocas ortográficas nas séries iniciais é uma etapa comum e imbricada de revelações acerca de como a criança lida com a relação entre grafema e representação fonológica. Nesse sentido, pretende-se observar o papel do contexto linguístico na ocorrência de trocas com as consoantes plosivas, já que tais trocas não são resultantes da complexidade do sistema ortográfico. Para tanto, serão analisados dados de 47 alunos matriculados nos $2^{\circ}, 3^{\circ}, 4^{\circ}$ e $6^{\circ}$ anos do ensino fundamental, coletados a partir de uma narrativa, com escrita espontânea, e uma lista de 233 palavras, com as plosivas distribuídas quanto à estrutura silábica, posição na palavra, contexto vocálico seguinte e tonicidade. Os resultados revelam que trocas ocorrem em sua maioria nas produções do $3^{\circ}$ ano e com plosivas labiais. Quanto aos contextos controlados, verifica-se que tonicidade e posição na palavra têm índices variáveis quanto ao predomínio de trocas, dependendo do ponto de articulação do segmento plosivo. No entanto, quanto ao contexto vocálico e à estrutura silábica, a ocorrência de trocas parece ser favorecida por vogais altas, assim como pela estrutura CCV.
\end{abstract}

Palavras-chave: Trocas ortográficas. Plosivas. Papel do contexto.

Abstract: The presence of orthographic changes in the primary school is a common stage and overlapping of revelations about how the child deals with the relationship between graphemes and phonological representations. In this way, we intend to observe the role of the context in the occurrence of with the stops consonants, since these are not the result of the complexity of the orthographic system. For that, we analyzed data from 47 participants enrolled in the 2nd, 3rd, 4th and 6th years of primary school, collected from a narrative, with spontaneous writing, and a list of 233 words, with the stops distributed in syllabic structure, position in the word, vocalic context and tonicity. The results reveal that most of the interchanges occur in the 3rd year and for labials stops. About the controlled contexts, it is verified that tonicity and position in the word have variable indices as to the predominance of interchanges depending on the stop; for the vowel context, the occurrence of exchanges seems to be favored by high vowels, as well as by the structure CCV.

Keywords: Orthographic changes. Stops. Linguistic contexto 


\section{Introdução:}

A presença de erros ortográficos ${ }^{1}$ em textos de crianças em seus anos iniciais de aprendizagem na escola está longe de poder ser considerada uma forma inadequada de escrita, antes disso, conforme menciona Miranda (2010), representa uma etapa da jornada da criança até a escrita padrão. Como a escrita carece de instrução formal para que seja efetivada, é natural que, nos anos iniciais do ensino fundamental, quando a criança começa a se familiarizar com essa modalidade da linguagem, haja uma maior incidência de erros, dentre os quais, as trocas ortográficas.

No ambiente escolar, esses erros, no entanto, ainda carecem de um melhor tratamento, para que seja desmitificada a ideia de que refletem desconhecimento do aluno. Na verdade, ao chegar na escola, o estudante já tem hipóteses acerca da escrita oriundas das práticas sociais em que está incluso, as quais deverão ser sistematizadas a fim de que uma relação fônica ortográfica seja estabelecida (FERREIRO; TEBEROSKY, 1999).

Durante essa sistematização, é natural que o aluno recorra à modalidade oral de sua língua para traçar hipóteses sobre sua escrita. Não por acaso, os erros ortográficos tendem a percorrer o mesmo caminho já traçado durante a aquisição da fala (ABAURRE, 2011). Dessa forma, observar os erros ortográficos significa ir além de estabelecer o que é certo ou errado, mas conceber, a partir de um ponto de vista linguístico, um olhar que possa alterar os valores já enraizados sobre tal tema.

Estudos já realizados apontam que esses erros podem ser classificados em dois grupos: alguns são decorrentes da influência fonético-fonológica ${ }^{2}$, enquanto outros denotam a complexidade do sistema ortográfico (ZORZI, 1997; GUIMARÃES, 2005). As plosivas - "p", "b”, "t”, “d”, "c" e "g" - apresentam, em

\footnotetext{
1 O termo erro não está sendo usado aqui de modo a estabelecer juízo de valor acerca da modalidade escrita da língua, mas no sentido de que o erro é uma forma necessária e provisória durante o processo de aprendizagem (MIRANDA, 2010).

2 O termo fonético-fonológico é aqui utilizado na perspectiva teórica da Fonologia Articulatória (BROWMAN; GOLDSTEIN, 1986, 1989, 1992).
}

geral, relação biunívoca entre grafemas e representação fonológica ${ }^{3}$. A exceção fica por conta das dorsais, que, quando seguidas das vogais "i" $e$ "e", são representadas pelos grafemas "qu" e "gu", requerendo a utilização do dígrafo para compor a adequada representação do som plosivo. Sendo assim, são constatados, em sua maioria, erros de motivação fonético-fonológica, que levam em conta a relação surda/sonora, a mudança de ponto de articulação e a omissão de letras.

Ainda, as trocas com os segmentos plosivos não têm sua ocorrência pautada em formas variáveis recorrentes no uso oral da língua, como ocorre, por exemplo, com a grafia das vogais médias altas, em que "e" e "o" podem ser grafados como "i" e "u", por exemplo, em posição átona final. Assim, "poti" para "pote" e "bolu" para "bolo".

No caso das plosivas, a ocorrência das trocas parece estar, portanto, relacionada com o contexto linguístico em que a plosiva se encontra, o qual pode indiciar ambientes mais ou menos favoráveis para a presença do erro. Tal contexto também pode ser revelador do estabelecimento de alterações na produção oral não percebíveis por uma simples análise de oitiva.

A fim de verificar o papel do contexto na ocorrência de trocas ortográficas, as plosivas foram observadas quanto ao contexto vocálico seguinte, estrutura silábica, posição na palavra e tonicidade, na escrita de 47 alunos matriculados nos $2^{\circ}, 3^{\circ}, 4^{\circ}$ e $6^{\circ}$ anos do ensino fundamental de uma escola pública, a partir da escrita de uma narrativa e de 233 palavras.

$\mathrm{Na}$ sequência, serão retomados alguns trabalhos que versam acerca da influência do contexto linguístico na escrita das consoantes plosivas, bem como apresentada a metodologia adotada para coleta de dados. Por fim, serão apresentados os resultados, conjuntamente com a

\footnotetext{
3 O trabalho foi desenvolvido sob a perspectiva da Fonologia Articulatória, prevendo, assim, uma maior aproximação entre fonética e fonologia, sendo o gesto - unidade simbólica e articulatória - o primitivo de análise, não mais o fonema apenas simbólico. Nesse sentido, a utilização de fonema e grafema, enquanto unidades abstratas não parece ser pertinente. Dessa forma, optou-se pelo uso de grafema, para representar a parte gráfica, e de representação fonológica para a unidade segmental.
} 
sua discussão, para que, então, sejam tecidas as considerações finais.

\section{A escrita das plosivas: o papel do contexto}

Diferentes trabalhos reportam a incidência de trocas ortográficas com os segmentos plosivos, tendo o contexto linguístico recebido papel de destaque na explicitação do processo de aprendizagem da escrita.

Zorzi (1997), em trabalho basilar acerca dos erros ortográficos presentes na escrita, realizado a partir da coleta escrita de 3 ditados e 2 redações, em 5 escolas públicas, em turmas de $1^{\underline{a}}$ a $4^{\underline{a}}$ série, classifica os erros com consoantes plosivas em duas categorias: omissão de letras e substituições de segmentos surdo/sonoro. As trocas relacionadas à sonoridade, no estudo do autor, são, em sua maioria, com as plosivas dorsais - "c", "qu", "g" e "gu" -, seguida das coronais - "t" e "d", e, por último, das labiais - "p" e "b". Nota-se, também, um predomínio de casos de dessonorização, evidenciado em todos os pares. Ocorrências que não se encaixam em nenhuma dessas categorias e que ocorrem mais raramente são classificados como outros erros, e competem aos casos em há troca de ponto de articulação, "cristi" ao invés de "triste", por exemplo.

Guimarães (2005), baseada em textos produzidos por crianças matriculadas nas séries iniciais do ensino fundamental, aponta que os erros em plosivas ocorrem, mais expressivamente, em 2 dos 6 sujeitos selecionados para a pesquisa. Esses erros aparecem, em sua maioria, nas plosivas dorsais e em menor quantidade nas plosivas labiais, assim como no estudo de Zorzi (1997). No que diz respeito ao contexto vocálico, uma menor quantidade de trocas diante de vogais altas era esperada traçando-se um paralelo com processos encontrados na aquisição da fala (LAMPRECHT, 1990) -, mas os dados não corroboram tal hipótese, já que muitas das trocas ocorrem justamente quando uma vogal alta vem após a plosiva.

Miranda e Matzenauer (2010), a partir do Banco de Textos sobre Aquisição da Linguagem Escrita (BATALE/FaE/UFPel), constituído por coletas de textos de escrita espontânea, com sujeitos das séries iniciais do ensino fundamental de duas escolas, evidenciam que a distinção de sonoridade é a maior dificuldade encontrada na escrita, assim como já havia sido observado por Zorzi (1997).

Reportam, também, que uma maior ocorrência de trocas é verificada nas plosivas dorsais, seguida das coronais e labiais. Quando considerados os casos de sonorização e dessonorização, as dorsais apresentam mais casos de dessonorização; a sonorização é mais recorrente nas coronais.

Miranda e Matzenauer (2010) destacam, ainda, a possível influência da posição da plosiva na palavra para a ocorrência dessas trocas com mudança de sonoridade. Os dados revelam que a maioria das trocas ocorre em posição medial, o que, segundo as autoras, é esperado, pois a posição inicial é mais proeminente e, portanto, seria mais facilmente percebida, o que facilitaria a sua adequada relação entre segmento e grafema.

Cristofolini (2008) realizou análise de dados de fala e escrita de 62 sujeitos, cursando a $4^{\underline{a}}$ série do ensino fundamental de uma escola localizada em Santa Catarina. A coleta de dados foi realizada com 267 crianças de 10 turmas de $4^{a}$ série. Esses alunos produziram, em sala de aula, três atividades de escrita: dois textos, sem tema definido, e um ditado.

A partir dos dados obtidos, Cristofolini (2008) verificou o predomínio de trocas, no que se refere à sonoridade, nas fricativas labiodentais, seguidas das plosivas coronais e dorsais. Quanto aos contextos linguísticos controlados, a autora salienta que o contexto tônico favorece a ocorrência das trocas, tanto no texto espontâneo como no ditado. Tal resultado não seria o esperado, considerando a hipótese de proeminência levantada por Miranda e Matzenauer (2010) para explicar a maior ocorrência de trocas na posição medial.

O contexto vocálico favorecedor à troca difere ao se comparar as modalidades de produção escrita, ou seja, ditado e texto espontâneo, sendo mais propícia à ocorrência de trocas com a vogal "i" nos textos espontâneos e com a vogal "a" no ditado. Os encontros consonantais representam menos de $10 \%$ 
das trocas encontradas, ainda que tal construção silábica seja a última a ser estabilizada na aquisição da oralidade (OLIVEIRA; MEZZOMO; FREITAS; LAMPRECHT, 2004). Tal índice pode ser resultado do baixo número de estímulos com essa estrutura,

A partir dos resultados apresentados por Zorzi (1997), Guimarães (2005), Miranda e Matzenauer (2010) e Cristofolini (2008), nota-se que a maior ocorrência de trocas aparece nas plosivas dorsais, seguida das coronais, e, por fim, nas labiais. Além disso, evidencia-se, também, que a maioria das trocas envolvendo esses segmentos são constatadas na relação surdo/sonora, sendo predominantes os casos de dessonorização.

Quanto aos contextos linguísticos considerados nos trabalhos, o contexto vocálico mostra-se relevante, já que há um predomínio de trocas com vogais altas, em especial "i" (CRISTOFOLINI, 2008). A posição medial parece ser favorecedora da ocorrência de troca, visto que os erros ocorrem com menor proeminência quando a plosiva inicia a palavra (MIRANDA; MATZENAUER, 2010). No que concerne à tonicidade, o contexto tônico parece favorecer à ocorrência de trocas (CRISTOFOLINI, 2008). A estrutura silábica, no entanto, carece de uma maior quantidade de dados que venham a corroborar se a estrutura CCV propicia ou não a ocorrência de trocas.

\section{Metodologia}

A fim de possibilitar a observação da aprendizagem da modalidade escrita da língua do período de ingresso na escola até o momento em que o aluno começa a estabelecer a compreensão dos princípios do sistema alfabético, a coleta de dados contou com a participação de 47 alunos, matriculados nos $2^{\circ}, 3^{\circ}, 4^{\circ}$ e $6^{\circ}$ anos $^{4}$ do ensino fundamental de uma escola pública localizada na cidade de Pelotas, RS. Tinha-se como objetivo manter 15 alunos em cada turma, no entanto, nem sempre o número de participantes devidamente autorizados pelos responsáveis foi suficiente. Assim, esses 47 sujeitos estão distribuídos conforme disposto no Quadro 1.

Quadro 1: Número de sujeitos por turma

\begin{tabular}{|c|c|}
\hline Turma & Número de sujeitos \\
\hline $2^{\circ}$ ano & 8 \\
\hline $3^{\circ}$ ano & 13 \\
\hline $4^{\circ}$ ano & 16 \\
\hline $6^{\circ}$ ano & 10 \\
\hline Total & 47 \\
\hline
\end{tabular}

Fonte: Elaborado pelas autoras

Esses participantes foram instruídos, primeiramente, a escrever uma narrativa a partir de imagens, apresentadas na Figura 1. Tal atividade permite observar como o participante lida com a grafia das plosivas em um contexto livre, quando tem a possibilidade de escolher as palavras que escreve.

A partir da Figura 1, foi constatada a produção recorrente de palavras como: par, bota, grama, sapato, bem como de variações dos verbos estar, andar e pescar. Nomes próprios como Guilherme, Lucas e Gustavo apareceram frequentemente quando os participantes por vezes nomeavam os personagens. É importante ressaltar que apenas as

Figura 1: Imagens que compõem a narrativa
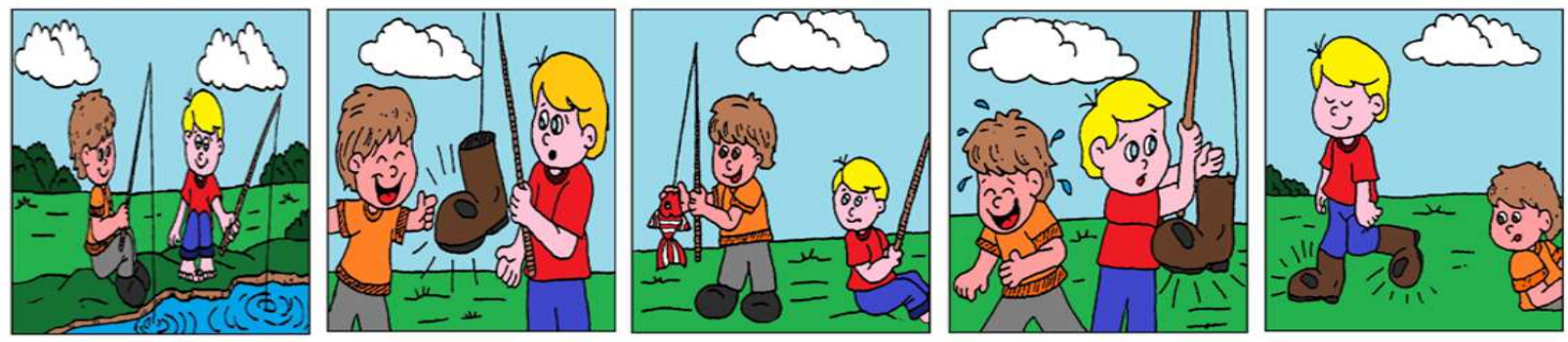

Fonte: Adaptado pelas autoras

\footnotetext{
${ }^{4} \mathrm{O}$ trabalho foi realizado a partir de um banco de dados, o qual não inclui coletas com alunos do $5^{\circ}$ ano.
} 
palavras que se enquadraram nos contextos estabelecidos para o ditado de imagens, que será descrito a seguir, foram consideradas, ficando de fora itens como peixe, por exemplo, que foi bastante utilizado.

$\mathrm{Na}$ sequência, foi proposto um ditado de imagens com 233 palavras exibidas aos alunos por meio de um Datashow. Essas palavras são constituídas por consoantes plosivas: (i) seguidas das vogais "a", "i", "u”; (ii) em sílaba com estrutura CV e CCV - seguida da líquida lateral e não lateral; (iii) em sílaba tônica e átona, e (iv) em posição inicial e medial na palavra. Nem todos os contextos foram preenchidos, visto que, em alguns casos, não havia palavras no léxico ou essas eram de difícil identificação por meio de figuras ${ }^{5}$. Dessa forma, o número de ocorrências para cada plosiva é o disposto no Quadro 2.

Quadro 2: Número de ocorrências por plosiva no ditado de imagens

\begin{tabular}{|c|c|c|c|}
\hline Plosiva & Ocorrências & Plosivas & Ocorrências \\
\hline $\mathrm{p}$ & 49 & $\mathrm{~b}$ & 49 \\
\hline $\mathrm{t}$ & 34 & $\mathrm{~d}$ & 24 \\
\hline $\mathrm{c}, \mathrm{qu}$ & 43 & $\mathrm{~g}, \mathrm{gu}$ & 34 \\
\hline
\end{tabular}

Fonte: Elaborado pelas autoras
Quadro 3: Exemplo da disposição das palavras para "b" conforme as variáveis linguísticas estabelecidas.

\begin{tabular}{|c|c|c|c|c|}
\hline \multirow{2}{*}{$/ p /$} & \multicolumn{2}{|c|}{ Início de palavra } & \multicolumn{2}{|c|}{ Meio de palavra } \\
\hline & Tônica & Átona & Tônica & Átona \\
\hline$|a|$ & palha & pavão & espaço & mapa \\
\hline & pano & panela & Espant & sopa \\
\hline
\end{tabular}

Fonte: Elaborado pelas autoras

A coleta de dados realizada é parte integrante do Projeto PICMEL ${ }^{6}$ (Programa de Iniciação a Ciência, Matemática, Engenharias e Letras) e todos os participantes foram autorizados a realizar os procedimentos previstos mediante Termo de onsentimento Livre e Esclarecido assinado por seus responsáveis. Todas as etapas foram realizadas na escola.

Após a finalização das coletas, os dados foram transcritos e contabilizados quanto à produção da forma alvo e à ocorrência de trocas. Foram também anotados os casos de produção de alvos distintos e de itens não produzidos. Tal contagem foi realizada por sujeito, considerando-se, primeiramente, uma descrição geral, sem divisão por variáveis, e, na sequência, uma descrição detalhada, levando-se em conta as variáveis selecionadas: contexto vocálico, estrutura silábica, tonicidade e posição na palavra.

Por fim, foi realizada análise estatística, por meio do software SPSS Statistics (versão 17.0), em que foram comparadas as variáveis linguísticas, bem como as quatro turmas participantes do estudo. Tal análise foi realizada a partir das médias de acerto de cada sujeito nos contextos delimitados. $O$ valor de $p$ menor do que 0.05 foi considerado significativo.

\footnotetext{
${ }^{6}$ Projeto PICMEL-FAPERGS/CAPES, coordenado pela Profa.

6 Projeto PICMEL-FAPERGS/CAPES, coordenado pela Profa.
Dr. Giovana Ferreira-Gonçalves (UFPel), processo nº. 03402551/14-6.
}

\footnotetext{
${ }^{5}$ Para maiores detalhes acerca de todas as palavras e imagens utilizadas, ver DAMÉ (2016)
} 


\section{Resultados e discussão}

Os dados de escrita coletados totalizam 7300 produções, das quais 6963 são correspondentes ao ditado e 337 à narrativa. Desse total, foram constatados 406 erros (5,6\%), sendo 401 no ditado, o que equivale a 5,5\%, e apenas 5 na narrativa, equivalentes a $0,07 \%$. No Quadro 3 , os erros são elencados por ano escolar.

Quadro 3: Percentual de erros na grafia de plosivas por ano na narrativa e no ditado

\begin{tabular}{|c|c|c|c|}
\hline & \multicolumn{3}{|c|}{ Narrativa } \\
\hline Ano & Possibilidades & Trocas & $\%$ \\
\hline $2^{\circ}$ ano & 35 & 0 & 0 \\
\hline $3^{\circ}$ ano & 74 & 3 & 4 \\
\hline $4^{\circ}$ ano & 139 & 2 & 1,4 \\
\hline $6^{\circ}$ ano & 89 & 0 & 0 \\
\hline Total & 337 & 5 & 0,07 \\
\hline \multicolumn{4}{|c|}{ Ditado } \\
\hline Ano & Possibilidades & Trocas & $\%$ \\
\hline $2^{\circ}$ ano & 1356 & 105 & 7,7 \\
\hline $3^{\circ}$ ano & 1618 & 157 & 9,7 \\
\hline $4^{\circ}$ ano & 2640 & 120 & 4,5 \\
\hline $6^{\circ}$ ano & 1349 & 19 & 1,4 \\
\hline Total & 6963 & 401 & 5,5 \\
\hline
\end{tabular}

Fonte: Elaborado pelas autoras

$\mathrm{Na}$ narrativa, erros são evidenciados apenas nos $3^{\circ}$ e $4^{\circ}$ anos. No $3^{\circ}$ ano, as trocas ocorreram nas palavras duas, Joca ${ }^{7}$ e tarde grafadas respectivamente como tuas, Joga e darde. Os dois erros verificados no $4^{\circ}$ ano foram nos itens triste e pescadores, escritos como driste e pesdores. No ditado, em todas as turmas foram verificados erros, sendo o maior percentual constatado no $3^{\circ}$ ano. Erros são verificados com frequência em itens como catedral - grafado de maneiras distintas, como caterrau, catreguau e categral, catebral - e grama grafado como rrema, grema e crama.

Essa maior recorrência no ditado pode ser explicada, em parte, pela metodologia, já que nessa etapa o participante não pode escolher a palavra a ser grafada, o que acontece na narrativa. Com esse poder de escolha, acredita-se que a criança priorize a escrita de palavras que tenha mais domínio. Não por acaso, no ditado, são verificados casos em que o participante tem dúvida do que grafar, mostrando justamente sua instabilidade quando diante de palavras que fogem de sua escrita cotidiana, como no exemplo apresentado na Figura 2.

Figura 2: Exemplo de dúvida entre a plosiva coronal e labial na grafia da palavra computador

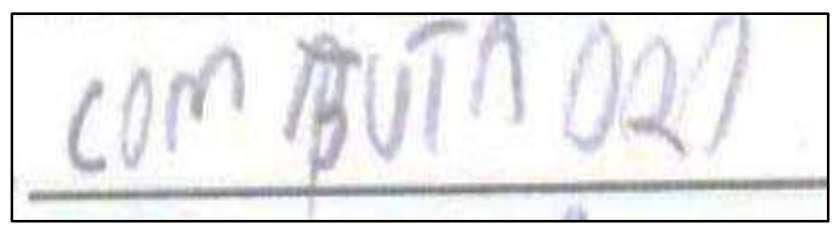

A maior ocorrência de erros no $3^{\circ}$ ano pode ser decorrência da instabilidade que o sistema fonéticofonológico da criança sofre ao se deparar com o da escrita. Isso provavelmente não é verificado no $2^{\circ}$ ano, pois é quando a criança começa a se deparar com as primeiras relações entre grafemas e representação fonológica. Ou seja, verifica-se uma reestruturação do sistema diante do ensino formal da escrita (AMARAL; FERREIRA-GONÇALVES, 2013; MIRANDA, 2014).

Considerando o ponto de articulação, nas narrativas e nos ditados, um maior número de trocas é observado nas plosivas labiais - com 23,9\% para "b" e 15,3\% para "p" -, e nas dorsais - com 20,4\% para "g/gu" e 14,5\% para "c/qu" - e, por fim, nas coronais - 13,1\% para "d" e 12,8\% para "t". Das 6 consoantes, "b" e "g" são as que apresentam os índices mais elevados de trocas, conforme observase no Gráfico 1.

\footnotetext{
${ }^{7}$ Nome dado ao personagem pelo participante.
} 
Gráfico 1: Percentual de trocas por plosiva considerando ditado e narrativa

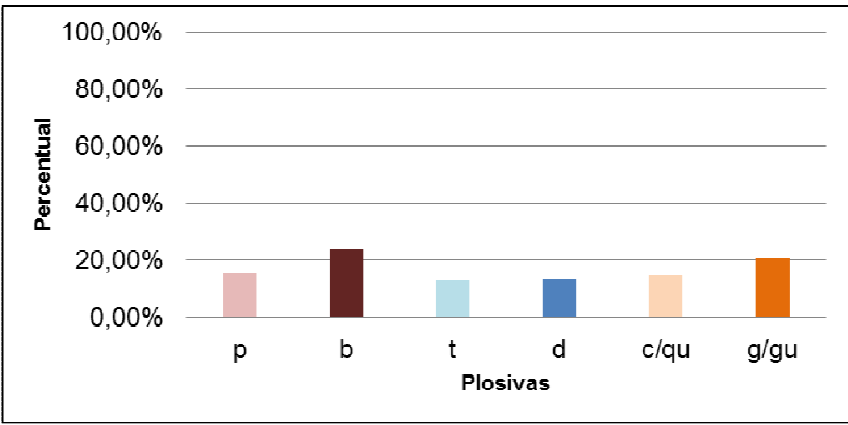

Fonte: Elaborado pelas autoras

Dessa forma, os resultados seriam distintos daqueles apontados por Zorzi (1997), Guimarães (2005), Miranda e Matzenauer (2010) e Cristofolini (2008), em que as trocas, em sua maioria, foram observadas nos segmentos dorsais ou mesmo coronais. Esse predomínio de trocas nas labiais, no entanto, pode ser resultado de um maior percentual de trocas de alguns participantes nesse segmento em específico. Verifica-se que, no $2^{\circ}$ ano, um dos participantes apresenta $65,6 \%$ das 29 trocas de "b" nessa série; no $4^{\circ}$ ano, outra criança evidencia $76,8 \%$ das 38 trocas na labial sonora.

Amalgamando as informações a respeito das plosivas e das trocas por escolaridade e, considerando apenas o ditado, verifica-se, no Gráfico 2, uma redução no número de trocas ao longo das séries, apesar de o $3^{\circ}$ ano apresentar, em geral, mais trocas do que o $2^{\circ}$, o que não se verifica apenas em "b" e "g/gu". Para "p", verifica-se, em ordem crescente, $1,4 \%$ de erros no $6 \stackrel{0}{\circ}$ ano, $2,5 \%$ no $2^{\circ}$ ano, $4,7 \%$ no $4^{\circ}$ ano e $8,7 \%$ no $3^{\circ}$ ano. Na contraparte sonora, novamente 0 6으 ano apresenta 0 menor percentual, com $0,4 \%$, seguido do $4^{\circ}$ ano com $6,8 \%$, e dos $2^{\circ}$ e $3^{\circ}$ anos com $9,9 \%$.

Somente um grafema apresenta $0 \%$ de erros, "t" no $6^{\circ}$ ano, seguido de $3,2 \%$ no $4^{\circ}$ ano, $6,1 \%$ no $2^{\circ}$ ano e $11,1 \%$ no $3^{\circ}$ ano. A sonora "d" segue a mesma ordem crescente, considerando os anos, de "t", com $0,7 \%$ de erros no $6^{\circ}$ ano, $4,9 \%$ no $4^{\circ}$ ano, $7,0 \%$ no $2^{\circ}$ ano e $14,7 \%$ no 3ํano. Para "q/qu", o menor índice é de $2,8 \%$ para os $2^{\circ}$ e $6^{\circ}$ anos, seguido do $4^{\circ}$ ano com $3,4 \%$ e, por fim, do $3^{\circ}$ com 8,3\%. Apenas para "g/gu", há índices inversamente proporcionais, ou seja, quanto mais adiantada a série, menos o índice de erros. No $6^{\circ}$ ano, há índice de $3,1 \%$, no $4^{\circ}$, de $4,4 \%$, no $3^{\circ}$, de $7,5 \%$ e no $2^{\circ}$, de $21,4 \%$.

Gráfico 2: Percentual de trocas por plosiva e escolaridade no ditado

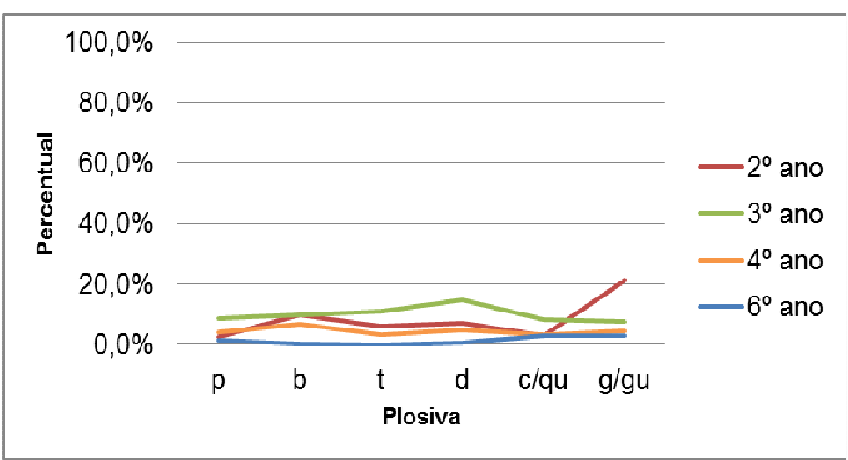

Fonte: Elaborado pelas autoras

A partir do Gráfico 2, observa-se, ainda, a maior probabilidade de trocas em plosivas sonoras, que levaria à dessonorização, sendo, em sua maioria, para "g/gu", nos $2^{\circ}$ e 6ำ anos, para "d" no $3^{\circ}$ ano e para "b" no $4^{\circ}$ ano. Essas trocas são, em geral, mudança de sonoridade $(61,6 \%)$. Haveria, portanto, uma maior ocorrência de dessonorização, como indiciado pela maior ocorrência de trocas em plosivas sonoras, ou seja, verifica-se predomínio de trocas das plosivas sonoras pelas surdas, assim como reportado por Zorzi (1997) e Miranda e Matzenauer (2010).

Essa maior ocorrência de trocas nesses segmentos pode ser consequência da ordem de aquisição das plosivas na fala, já que não só no Português (OLIVEIRA; MEZZOMO; FREITAS; LAMPRECHT, 2004; FREITAS, 2004), como também em outras línguas (KONG; BECKMAN; EDWARDS, 2012) é atestado que as plosivas surdas são adquiridas primeiramente. Sendo assim, seria esperada uma maior instabilidade nas plosivas sonoras nas primeiras etapas de aquisição da escrita. Outros tipos de trocas, no entanto, também são evidenciadas, como é possível observar no Quadro 4, que revela o percentual de modalidade de trocas por escolaridade. 
Quadro 4: Percentual de trocas ortográficas por escolaridade e modalidade de trocas

\begin{tabular}{|c|c|c|c|c|c|c|}
\hline Ano & $\begin{array}{c}\text { Surda/s } \\
\text { onora }\end{array}$ & $\begin{array}{c}\text { Mudança } \\
\text { de ponto de } \\
\text { articulação }\end{array}$ & $\begin{array}{c}\text { Mudança } \\
\text { de modo de } \\
\text { articulação }\end{array}$ & $\begin{array}{c}\text { Apagamento } \\
\text { da plosiva }\end{array}$ & Outros & Total \\
\hline $\begin{array}{c}2^{\circ} \\
\text { ano }\end{array}$ & $65,7 \%$ & $13,3 \%$ & $14,3 \%$ & $5,8 \%$ & $1,9 \%$ & 105 \\
\hline $\begin{array}{c}3^{\circ} \\
\text { ano }\end{array}$ & $66,9 \%$ & $29,3 \%$ & $1,3 \%$ & $2,5 \%$ & -- & 157 \\
\hline $\begin{array}{c}4^{\circ} \\
\text { ano }\end{array}$ & $47,5 \%$ & $46,7 \%$ & $0,8 \%$ & $5,0 \%$ & -- & 120 \\
\hline $\begin{array}{c}6^{\circ} \\
\text { ano }\end{array}$ & $89,6 \%$ & $5,2 \%$ & - & $5,2 \%$ & -- & 19 \\
\hline Geral & $61,6 \%$ & $29,2 \%$ & $4,5 \%$ & $4,2 \%$ & $0,5 \%$ & 401 \\
\hline
\end{tabular}

Fonte: Elaborado pelas autoras

Os maiores percentuais ficam por conta das trocas na relação surda/sonora (Figura 3) em todos os anos. Em geral, a mudança de ponto de articulação (Figura 4) é o segundo tipo de troca que mais ocorre, com $29,2 \%$, seguida da mudança de modo (Figura 5), com 4,5\%. Por fim, com 4,2\%, aparecem casos de apagamento da plosiva (Figura 6). Os casos classificados como outros (Figura 7) referem-se a casos em que as plosivas são grafadas, mas de um modo diferente do esperado.

Figura 3: Dessonorização em canguru tubarão

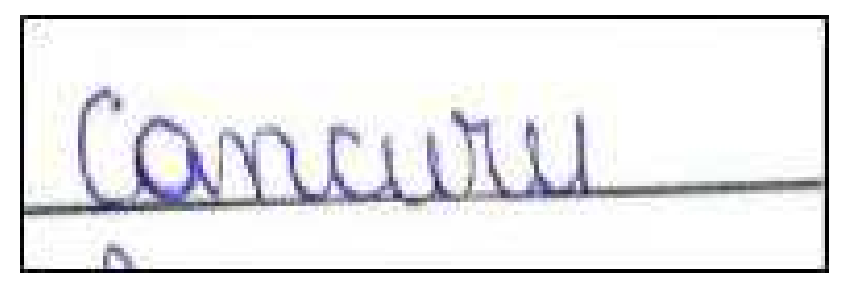

Figura 4: Mudança de ponto de articulação em

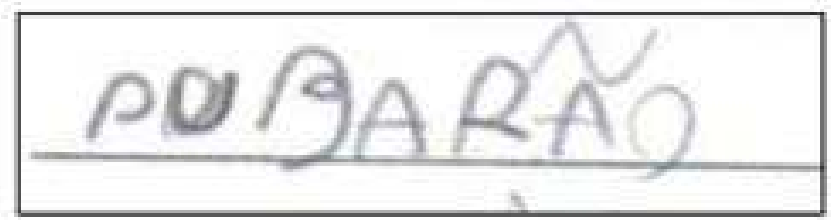

Figura 5: Mudança de modo de articulação em zebu

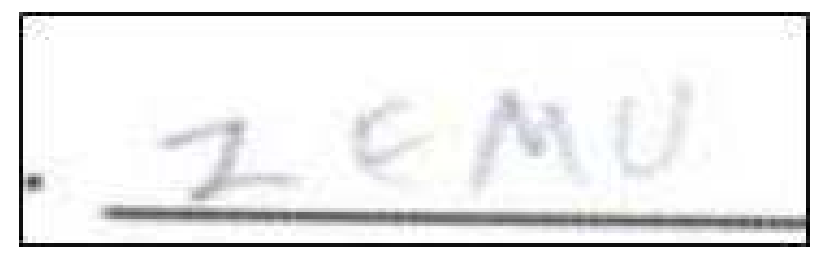

Figura 6: Apagamento da plosiva em primo ${ }^{8}$

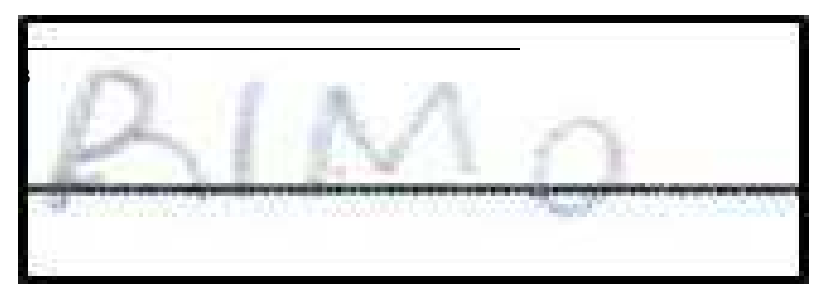

Figura 7: Grafia de clarão

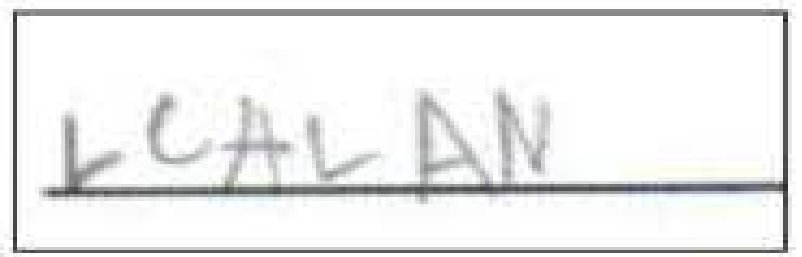

No $4^{\circ}$ ano chama atenção 0 alto índice de trocas em que há mudança de ponto de articulação. Essas trocas, novamente, refletem a escrita de um único participante - o mesmo com alto índice de trocas na grafia da plosiva "b" -, o qual realiza a troca dessa consoante por "d" possivelmente devido à similaridade entre a grafia dessas duas consoantes (Figura 8). Essa troca, possivelmente, não apresenta relação com a conexão estabelecida entre grafema e representação fonológica mas a simples rotação da grafia do grafema em questão diante da semelhança entre ambos.

Figura 8: Troca de ponto de articulação em fábula

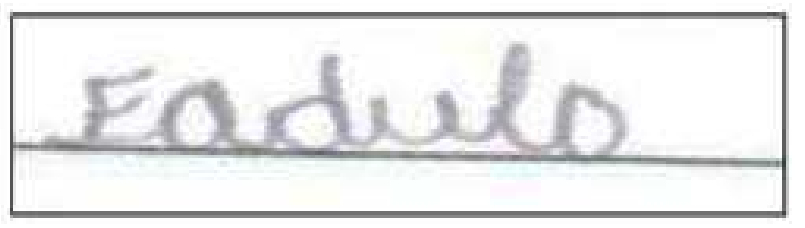

Com relação aos contextos linguísticos controlados, considerando todas as turmas, verificouse, a partir da Tabela 1, que para tonicidade as plosivas " $\mathrm{t}$ " e "g/gu" apresentam maiores percentuais de trocas em posição átona, as demais, com exceção de "b", que tem índices iguais em sílaba átona e tônica, evidenciam mais trocas em sílaba tônica. Mostrou-se significativa a influência do contexto tônico, para a escrita adequada de "t" - exemplos nas Figuras de 9 a 12 -, evidenciada por meio do teste Wilcoxon $(Z=-2,383, p=0,017)$. O predomínio de trocas em contexto átono é esperado, segundo Sanches (2003), devido à maior sonorização apresentada por sílabas tônicas, o que facilita sua identificação.

Outra interpretação para esse caso seria o registro do " $r$ " sobre a grafia do "p", tendo o participante considerado que a plosiva já estaria grafada. No entanto, o participante que realizou tal erro também o realiza em outros dois casos, para sogra, grafada como sorar e gladiador, grafado como Ihadiador, o que corroboraria a hipótese de apagamento 
Figuras 9 e 10: Exemplos de "t" em contexto tônico nas palavras taça e tribo
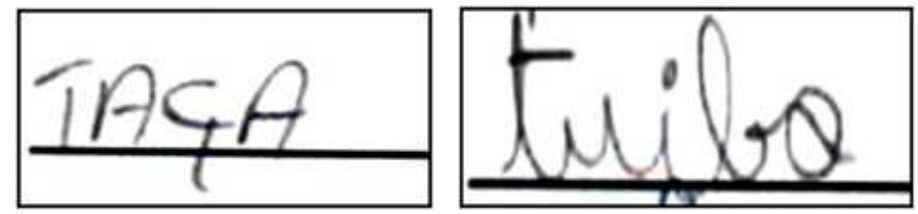

Figuras 11 e 12: Exemplos de 't' em contexto átono e em posição inicial nas palavras tucano e triângulo
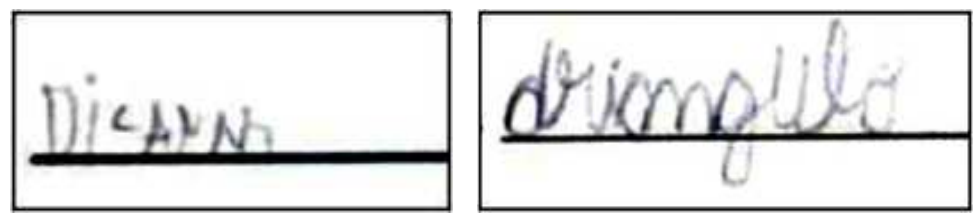

Figuras 13 e 14: Exemplos de 't' em posição medial nas palavras elétrico e estufa
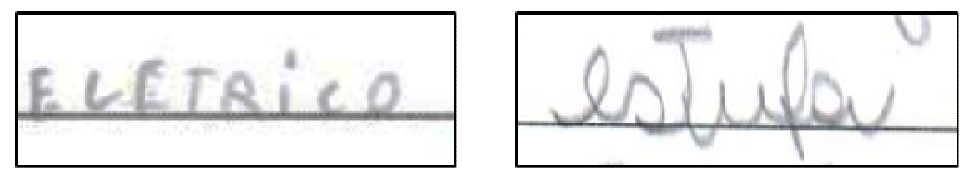

No que se refere à posição da plosiva na palavra, a posição medial apresenta maior percentual de trocas para "p", "c/qu" e "g/gu". Para "b", "t" e "d", a posição inicial parece favorecer a troca. A posição medial, conforme exemplos nas Figuras de 11 a 14, mostrou-se relevante significativamente para a ocorrência adequada de " $\mathrm{t}$ ", a partir do teste Wilcoxon $(\mathrm{Z}=-2,104, p=0,035)$. A posição medial das plosivas na palavra, conforme Miranda e Matzenauer (2010), tenderia a influenciar na ocorrência de trocas, pois, nessa posição, sua percepção tende a ser menos saliente, fato não corroborado estatisticamente nos resultados do presente artigo.

No que diz respeito ao contexto vocálico, verifica-se nas vogais altas os maiores percentuais de trocas, com exceção de "t", em os maiores índices de trocas aparecem em "a". Estatisticamente, foi evidenciada, primeiramente por meio do teste Friedman $\left(\left(x^{2}(2)=16,687, p=0,000\right)\right.$, diferença significativa na grafia de "b". A partir do pareamento das três vogais, foi verificado, por meio do teste Wilcoxon $(Z=-2,972, p=0,003)$, para $/ a / x / i /$, e $(Z=$ $3,517, p=0,000)$ para $/ a / x / u /$, que a vogal "a" favorece a grafia esperada dessa consoante, conforme exemplos apresentados nas Figuras de 15 a 17. De acordo com Cristofolini (2008), o contexto vocálico com maior recorrência de trocas diz respeito às vogais "a" e "i", o primeiro caso encontrado em ditados, e o segundo, em produção livre, o que condiz com os resultados evidenciados quanto ao predomínio de trocas no que concerne à vogal alta.

Tabela 1: Percentual geral de acertos e trocas por plosiva, considerando-se a tonicidade, a posição na palavra, o contexto vocálico e a estrutura silábica.

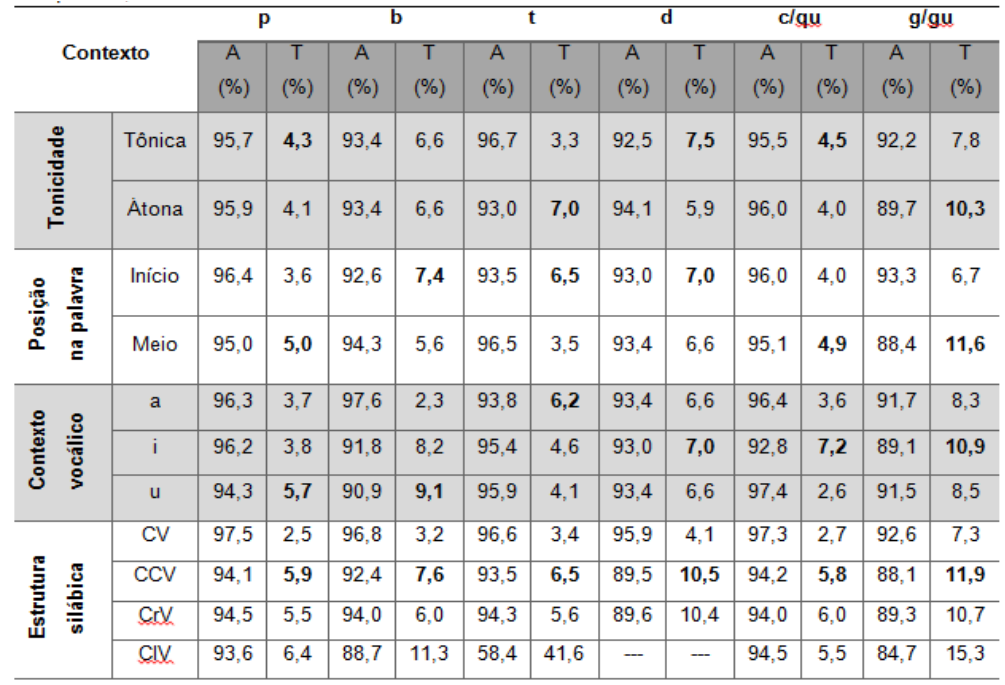

Legenda: A - Acertos, T - Trocas, --- - Não há dados disponíveis

Fonte: Elaborado pelas autoras 
Figuras 15, 16 e 17: Exemplos de "b' em contexto vocálico de "a", "i" e "u" nas palavras balé, lábios e buzina

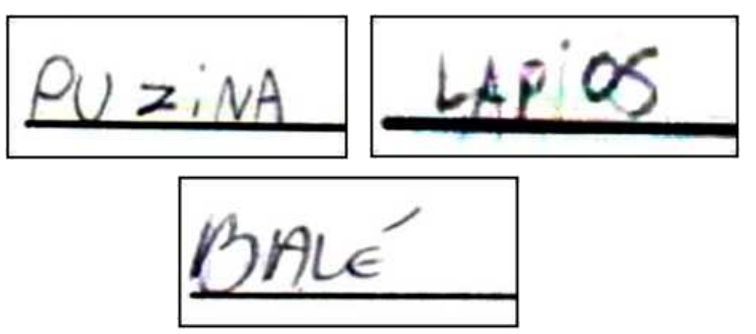

Quanto à estrutura silábica, para todas as plosivas, observam-se maiores índices de trocas na construção CCV. A estrutura CV se mostrou mais provável à ocorrência de acertos para "p" $(Z=-2,483$, $p=0,013)$, "t" $(Z=-2,561, p=0,010)$ e "d" $(Z=-$ 2,876, $p=0,004)$, significância constatada por meio do teste Wilcoxon, logo, as trocas são mais frequentes em sílabas CCV, conforme exemplos nas Figuras de 18 a 20. No que diz respeito à estrutura silábica, era esperado que uma estrutura que foge ao padrão CV, e que abrange dois segmentos de caráter consonantal, fosse mais suscetível à ocorrência de trocas, o que foi confirmado pelos resultados.

Figuras 18, 16 e 17: Exemplos de "b' em contexto vocálico de "a", "i" e "u" nas palavras praia, patrulha e madrugada
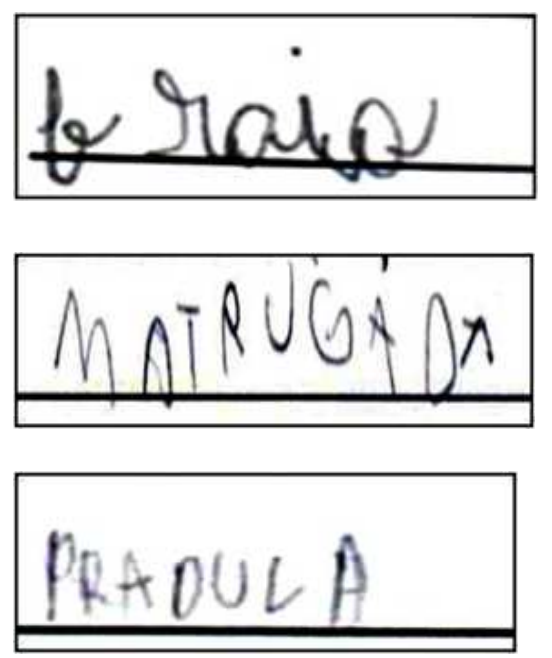

\section{Considerações Finais}

A ocorrência de trocas com os segmentos plosivos permanece sendo evidenciada, ainda que em baixos índices, nas séries iniciais do ensino fundamental. Verificou-se que as trocas são mais expressivas quando o participante não tem o controle sobre o que deve escrever, ou seja, na lista de palavras. De modo não esperado, as plosivas labiais, em especial a sonora, apresentou-se como o segmento com maiores índices de trocas, no entanto, tal resultado parece ser oriundo das trocas de sujeitos específicos em algumas das turmas.

As plosivas surdas apresentam os maiores percentuais de trocas e, considerando que essas acontecem em sua maioria na relação surda/sonora, indicia-se o predomínio de casos de dessonorização. Quanto aos contextos controlados, os percentuais dão indícios de que a tonicidade e a posição na palavra tendem a variar sua importância de uma plosiva para outra; para o contexto vocálico, as vogais altas parecem favorecer a ocorrência de trocas, assim como a estrutura CCV. Tais resultados são significativos para plosivas, o que demonstra que 0 contexto pode ser considerado um dos fatores que levam à ocorrência de trocas com esses segmentos.

Contudo, a escrita dos segmentos plosivos parece ainda prescindir de detalhes outros que venham a explicar sua motivação - como parâmetros acústicos e articulatórios (CRISTOFOLINI, 2008; DAMÉ, 2016; DAMÉ; FERREIRA-GONÇALVES, 2017; SANCHES, 2003) -, mas observar o contexto em que tais trocas ocorrem mostra-se relevante, visto que pode vir a auxiliar no melhor entendimento do processamento desses segmentos e de que forma se dá sua relação com os demais segmentos na palavra.

\section{Referências}

ABAURRE, M. B. M. A relação entre escrita espontânea e representações linguísticas subjacentes, Verba Volant, Vol. 2, pp.167-200, Pelotas: Editora UFPEL, 2011.

AMARAL, V. S.; FERREIRA-GONÇALVES, G. Produções orais e escritas dos diotngos [aj], [ej] e 
[ow]: dados de São José do Norte/RS. Diadorim (Rio de Janeiro), v. 14, p. 127-154, 2013.

BROWMAN, C.; GOLDSTEIN, L. Towards an articulatory phonology. Phonology Yearbook, 3: 219-252, 1986.

Articulatory Gestures as Phonological Units. Phonology, 6. pp. 201-51, 1989.

Articulatory Phonology: an overview. Phonetica, 49: 155-180, 1992.

CRISTOFOLINI, C. Trocas ortográficas: um estudo a partir de análises acústicas. Dissertação de Mestrado. Programa de Pós-Graduação em Linguística. Universidade de Santa Catarina, 2008.

DAMÉ, V. S. Aquisição da escrita das consoantes plosivas: aspectos acústicos e articulatórios. Dissertação (Mestrado em Letras). Programa de Pós-Graduação em Letras, Universidade Federal de Pelotas, 2016.

DAMÉ, V. S.; FERREIRA-GONÇALVES, G. Trocas ortográficas de consoantes oclusivas no Português Brasileiro: dados de Pelotas/RS Brasil. Signótica, v. 29, p. 504-527, 2017.

FERREIRO, E.; TEBEROSKY, A. Psicogênese da língua escrita. Porto Alegre: Artmed, 1999.

FREITAS, G. C. M. Sobre a aquisição das plosivas e nasais. In: LAMPRECHT, R (Org.). Aquisição Fonológica do Português. Porto Alegre: Artmed, 2004.

GUIMARÃES. M, R. Um estudo sobre a aquisição da ortografia nas séries iniciais. Dissertação (Mestrado em Educação) - Faculdade de Educação, UFPel, Pelotas, 2005.

KONG, E. J.; BECKMAN, E.; EDWARDS, J. Voice Onset time is necessary but not Always suficiente to describe acquisition of voiced stops: The cases of Greek and Japanese. Journal of Phonetics, 40, 725-744, 2012.

LAMPRECHT, R. R.; OLIVEIRA, C. C.; MEZZOMO, C. L.; FREITAS, G. C. M. Cronologia da aquisição dos segmentos e das estruturas silábicas. In: LAMPRECHT, R. (Org.). Aquisição Fonológica do Português. Porto Alegre: Artmed, 2004.

LAMPRECHT, R., R. Perfil de aquisição normal da fonologia do Português. Descrição longitudinal de 12 crianças: 2:9 a 5:5. Tese (Doutorado em Letras) - Instituto de Letras e Arte, PUCRS, 1990.
MIRANDA, A. R. M. Um estudo sobre o erro ortográfico. In: HEINING, O. L.; FRONZA, C. A. (Org.). Diálogos entre linguística e educação. 1 ed. v. 1, p. 141-162. Blumenau: EDIFURB, 2010.

A Fonologia em dados de escrita inicial de crianças brasileiras. Revista Linguística, vol. 30, n. 2, p. 45-80, 2014.

MIRANDA, A. R. M.; MATZNAUER, C. L. B. Aquisição da fala e da escrita: relações com a Fonologia. Cadernos de Educação. Pelotas, n. 35. p. 359404, jan./abr. 2010.

OLIVEIRA, C. C.; MEZZOMO, C. L.; FREITAS, G. C. M.; LAMPRECHT, R. R. Cronologia da aquisição dos segmentos e das estruturas silábicas. In: LAMPRECHT, R. (Org.). Aquisição Fonológica do Português. Porto Alegre: Artmed, 2004.

SANCHES, A. P. Análise espectrográfica da fala de crianças com trocas grafêmicas nos plosivos surdos e sonoros. Dissertação (Mestrado): Universidade Federal de Maringá, 2003.

ZORZI, J. L._A apropriação do sistema ortográfico nas quatro primeiras séries do $1^{\circ}$ grau. Unicamp. Faculdade de Educação. Campinas,1997.

\section{COMO CITAR ESSE ARTIGO}

DAMÉ, Vergília Spiering; FERREIRA GONÇALVES, Giovana. AS PLOSIVAS NAS SÉRIES INICIAIS: O PAPEL DO CONTEXTO NA OCORRÊNCIA DE TROCAS ORTOGRÁFICAS. Signo, Santa Cruz do Sul, v. 43, n. 77, jul. 2018. ISSN 1982-2014. Disponível em: <https://online.unisc.br/seer/index.php/signo/article/view/11531>. Acesso em: . doi: http://dx.doi.org/10.17058/signo.v43i77.11531. 